\title{
Visual and production similarity of the handshapes of the American manual alphabet
}

\author{
JOHN T. RICHARDS \\ IBM Thomas J. Watson Research Center, Yorktown Heights, New York \\ and \\ VICKI L. HANSON \\ Haskins Laboratories, New Haven, Connecticut
}

\begin{abstract}
Two experiments were performed to examine the nature of handshape similarity for the 26 elements of the American manual alphabet. Forty deaf college students, half native (first language) signers of American Sign Language and half nonnative signers, participated in the study. In Experiment 1, subjects were asked to base their judgments on visual characteristics of the shapes. In Experiment 2, they were asked to base their judgments on aspects of manual shape production. Hierarchical clustering and multidimensional scaling analyses showed the two sets of judgments to be quite similar. No clear differences were found between native and nonnative signers in either experiment. These data provide a basis for the future manipulation and detection of manual coding in the processing of verbal stimuli.
\end{abstract}

In recent years, there has been considerable interest in the cognitive processes of deaf persons (see, e.g., Conrad, 1979; Furth, 1973; Neville, Kutas, \& Schmidt, 1982), frequently focusing on the use of speech-based and manual codes in the processing of verbal materials (Bellugi, Klima, \& Siple, 1975; Dodd \& Hermelin, 1977; Hanson, 1982a; Quinn, 1981; Treiman \& Hirsh-Pasek, 1983). Experimentation in this area often requires an understanding of stimulus similarity so that confusability and selective interference can be systematically varied (see, e.g., Hanson, Liberman, \& Shankweiler, 1984; Locke \& Locke, 1971). Although several studies have characterized the phonetic similarity of common stimuli (e.g., Miller \& Nicely, 1955, for English consonants; Conrad, 1964, for letter names), an adequate characterization of comparable manual stimuli has not been done.

Two different forms of manual language are used by deaf individuals in the course of conversation: fingerspelling and sign. Fingerspelling, like spoken languages, uses temporal sequencing of constituent elements to convey morphemes. The handshapes shown in Figure 1 constitute these elements. Each is a one-handed representation of a letter in the American manual alphabet. Words are spelled out by producing these handshapes sequentially in the space to the side of the signer's face.' Although many of the shapes are similar to those used in sign, fingerspelling does not use the other parameters essential to

This work was supported, in part, by Grant NS-18010 from the National Institute of Neurological and Communicative Disorders and Stroke. We thank John Conti for his drawings of handshapes used in the first experiment and Nancy Fishbein for testing the subjects. Requests for reprints should be sent to John Richards at the IBM Thomas J. Watson Research Center, P.O. Box 218. Yorktown Heights, NY 10598. sign language in making linguistic distinctions (Klima \& Bellugi, 1979; Stokoe, Casterline, \& Croneberg, 1965). Fingerspelling is used to convey specific names or words for which no sign equivalent exists and can be used to convey entire conversations (the Rochester method).

The present paper focuses on the visual and production similarity of the 26 elements of the American manual alphabet. Deaf college students, both native (first language) and nonnative signers of American Sign Language (ASL), served as informants. Previous studies had examined only subsets of these handshapes (Lane, BoyesBraem, \& Bellugi, 1976; Locke, 1970; Stungis, 1981), or had used hearing subjects with limited prior fingerspelling experience (Weyer, 1973). ${ }^{2}$ Experiment 1 examined the similarity of handshapes as visual objects. Experiment 2 examined production similarity.

\section{EXPERIMENT 1}

\section{Method}

Stimuli. Simple line drawings of the 26 handshapes of the American manual alphabet were the stimuli in this experiment. These handshapes and the letters they represent are shown in Figure 1 (note that the letters did not appear with the experimental stimuli). Each handshape was individually rendered on a card measuring approximately $21 / 2 \times 31 \frac{1}{4}$ in.

Procedure. Subjects were tested individually. At the beginning of an experimental session, the 26 cards were laid out in front of the subject. The arrangement was random, with the constraint that each handshape appear in the proper orientation (i.e., the top of each handshape was always to be on the top).

The subjects were instructed to sort the handshapes into piles on the basis of visual similarity. The following written instructions were presented to the subjects: "The 26 letters of the manual alphabet are laid out in front of you. Begin by looking at each handshape and paying attention to how it looks. Then put the handshapes into piles, so that handshapes that look similar are in the same pile. You 

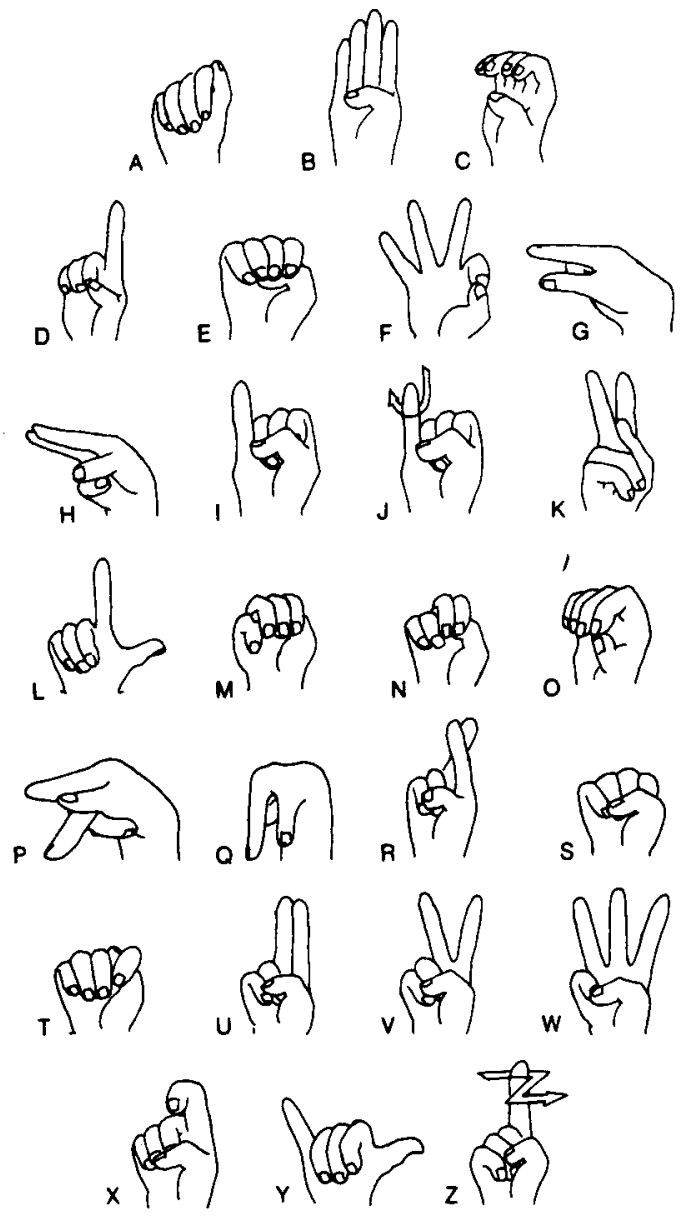

Figure 1. Drawings used as stimuli in Experiment 1. can have as many piles as you wish and you can have any number of handshapes in each pile. You can change your mind as often as you like until your arrangement seems best." The experimenter, a deaf native signer of ASL, discussed the instructions with each subject in sign to make sure that the task was clearly understood.

Subjects. The subjects for the experiment were 20 prelingually deaf students from Gallaudet College. Half were native signers of ASL (having learned ASL as a first language from their deaf parents) and half were not. The nonnative signers reported a minimum of 13 years' signing experience. On the average, they had learned to sign at the age of 6.2 years; the mean length of signing experience for these subjects was 18.7 years. All subjects were paid for their participation in this 15-min experiment.

\section{Results and Discussion}

Table 1 summarizes the number of subjects who sorted a given handshape pair into the same pile. A score of 20 thus represents the maximum possible interitem similarity. To discover any structure inherent in this matrix (to discover, that is, how the handshapes might be naturally grouped), we applied Johnson's (1967) hierarchical clustering procedure (after first converting the raw frequency counts to a dissimilarity matrix). Separate analyses using the maximum and minimum methods for determining intercluster distance were conducted. Johnson observed that the two methods yield very similar results (at least with the sort of data considered in his report). This was true of the present experiment, in which the maximum and minimum results shared 9 of the 10 letter-pair clusters. Johnson also noted that when the results of the maximum and minimum methods diverge, those obtained with the maximum method appear to be more interpretable. In Figure 2, we show the clusterings produced by the maximum method. In this figure, similarity decreases as one goes from the top to the bottom and clusters are indicated by adjacent $\times s$. Thus, $\mathrm{M}$ and $\mathrm{N}$ can be seen to

Table 1

Number of Subjects Sorting Handshape Pairs Into Same Pile on the Basis of Visual Similarity in Experiment 1

\begin{tabular}{|c|c|c|c|c|c|c|c|c|c|c|c|c|c|c|c|c|c|c|c|c|c|c|c|c|c|}
\hline & A & B & $\mathbf{C}$ & D & $\mathbf{E}$ & $\mathbf{F}$ & $\mathbf{G}$ & $\mathbf{H}$ & I & $\mathrm{J}$ & $\mathbf{K}$ & $\mathbf{L}$ & $\mathbf{M}$ & $\mathbf{N}$ & 0 & $\mathbf{P}$ & $\mathbf{Q}$ & $\mathbf{R}$ & $S$ & $\mathrm{~T}$ & $\mathbf{U}$ & $\mathbf{V}$ & $\mathbf{W}$ & $X$ & $\mathrm{Y}$ \\
\hline B & 2 & & & & & & & & & & & & & & & & & & & & & & & & \\
\hline C & 5 & 0 & & & & & & & & & & & & & & & & & & & & & & & \\
\hline D & 0 & 5 & 0 & & & & & & & & & & & & & & & & & & & & & & \\
\hline E & 15 & 1 & 7 & 0 & & & & & & & & & & & & & & & & & & & & & \\
\hline $\mathbf{F}$ & 0 & 6 & 0 & 4 & 0 & & & & & & & & & & & & & & & & & & & & \\
\hline G & 0 & 0 & 0 & 0 & 0 & 0 & & & & & & & & & & & & & & & & & & & \\
\hline H & 0 & 4 & 0 & 1 & 0 & 1 & 8 & & & & & & & & & & & & & & & & & & \\
\hline I & 0 & 3 & 0 & 8 & 0 & 4 & 0 & 0 & & & & & & & & & & & & & & & & & \\
\hline $\mathbf{J}$ & 0 & 2 & 0 & 6 & 0 & 2 & 0 & 0 & 18 & & & & & & & & & & & & & & & & \\
\hline $\mathbf{K}$ & 0 & 3 & 0 & 4 & 0 & 7 & 0 & 0 & 4 & 2 & & & & & & & & & & & & & & & \\
\hline $\mathbf{L}$ & 0 & 4 & 0 & 14 & 0 & 4 & 0 & 1 & 8 & 6 & 4 & & & & & & & & & & & & & & \\
\hline $\mathbf{M}$ & 15 & 1 & 4 & 0 & 16 & 0 & 0 & 0 & 0 & 0 & 0 & 0 & & & & & & & & & & & & & \\
\hline $\mathbf{N}$ & 15 & 1 & 4 & 0 & 16 & 0 & 0 & 0 & 0 & 0 & 0 & 0 & 20 & & & & & & & & & & & & \\
\hline 0 & 9 & 0 & 16 & 0 & 11 & 0 & 0 & 0 & 0 & 0 & 0 & 0 & 8 & 8 & & & & & & & & & & & \\
\hline $\mathbf{P}$ & 0 & 0 & 0 & 0 & 0 & 1 & 5 & 5 & 0 & 1 & 10 & 0 & 0 & 0 & 0 & & & & & & & & & & \\
\hline $\mathbf{Q}$ & 0 & 0 & 0 & 0 & 0 & 0 & 17 & 5 & 0 & 1 & 0 & 0 & 0 & 0 & 0 & 6 & & & & & & & & & \\
\hline $\mathbf{R}$ & 0 & 4 & 0 & 6 & 0 & 4 & 1 & 2 & 5 & 3 & 8 & 6 & 0 & 0 & 0 & 4 & 1 & & & & & & & & \\
\hline $\mathbf{S}$ & 15 & 1 & 8 & 0 & 17 & 0 & 0 & 0 & 0 & 0 & 0 & 0 & 13 & 13 & 12 & 0 & 0 & 0 & & & & & & & \\
\hline $\mathrm{T}$ & 17 & 1 & 5 & 0 & 14 & 0 & 0 & 0 & 0 & 0 & 0 & 0 & 16 & 16 & 9 & 0 & 0 & 0 & 14 & & & & & & \\
\hline $\mathbf{U}$ & 0 & 11 & 0 & 5 & 0 & 5 & 0 & 10 & 4 & 2 & 6 & 5 & 0 & 0 & 0 & 0 & 0 & 6 & 0 & 0 & & & & & \\
\hline V & 0 & 3 & 0 & 4 & 0 & 10 & 0 & 1 & 4 & 2 & 14 & 4 & 0 & 0 & 0 & 5 & 0 & 7 & 0 & 0 & 7 & & & & \\
\hline W & 0 & 6 & 0 & 5 & 0 & 13 & 0 & 2 & 4 & 2 & 10 & 4 & 0 & 0 & 0 & 2 & 0 & 5 & 0 & 0 & 7 & 15 & & & \\
\hline X & 2 & 1 & 7 & 4 & 2 & 1 & 0 & 1 & 2 & 1 & 1 & 4 & 2 & 2 & 5 & 0 & 0 & 3 & 3 & 2 & 2 & 1 & 1 & & \\
\hline$Y$ & 3 & 1 & 2 & 1 & 3 & 3 & 0 & 0 & 3 & 2 & 1 & 2 & 3 & 3 & 2 & 0 & 0 & 1 & 3 & 3 & 1 & 2 & 2 & 3 & \\
\hline $\mathbf{Z}$ & 0 & 2 & 0 & 15 & 0 & 1 & 0 & 1 & 5 & 6 & 2 & 10 & 0 & 0 & 0 & 1 & 1 & 4 & 0 & 0 & 3 & 2 & 1 & 4 & 1 \\
\hline
\end{tabular}


$\times \times \times \times \times \times \times \times \times \times \times \times$ $\times \times \times \times \times \times \times \times \times \times \times \times$ $\times \times \times \times \times \times \times \times \times \times \times$ $\times \times \times \times$

$\times \times \times \times \times \times \times \times \times \times \times$ $\times \times \times \times \times \times \times \times \times \times \times \times \times \times x$ $\times \times \times \times \times \times \times \times \times \times \times \times \times \times \times \times$ $\times \times \times \times \times \times \times \times \times \times \times \times \times \times \times \times$ $\times \times \times \times \times \times \times \times \times \times \times \times \times \times \times \times$

$x \times$

$\times \times \times \times \times \times \times \times \times \times \times$ $\times \times \times \times \times \times \times \times \times \times \times$ $\times \times \times \times \times \times \times \times \times \times \times \times \times \times \times \times \times \times \times \times \times$ $\times \times \times \times \times \times \times \times \times \times \times \times \times \times \times \times$ $\times \times \times \times \times \times \times \times \times \times \times \times \times \times \times \times$ $\times \times \times \times \times \times$ $\times \times \times \times \times \times \times \times \times \times \times \times \times \times \times \times \times \times \times$ $\times \times \times \times \times \times \times \times \times \times \times \times \times \times \times \times \times \times \times$ $\times \times \times \times \times \times \times \times \times \times \times \times \times \times \times \times \times \times \times$ $x$

$x \times x \times x \times$ $x \times \times \times \times \times$ $\times \times \times \times \times \times \times \times \times \times \times \times \times \times \times \times \times \times$ $\times \times \times \times \times \times \times \times \times \times \times \times \times \times \times \times \times \times$ $\times \times \times \times \times \times \times \times \times \times \times \times \times \times \times \times \times \times$

$$
\begin{array}{r}
\times \\
\times \times \times \times \times \times \times \times \times \times \times \times \times \times \times \times \\
\times \times \times \times \times \times \times \times \times \\
\times \times \times \times \times \\
\times \times \times \times \\
\times \times \times \\
\times \times \times \times
\end{array}
$$
$\times \times \times \times \times \times \times \times \times \times \times \times \times \times \times \times \times \times$ $\times \times \times \times \times \times \times \times \times \times \times \times \times \times \times \times \times \times$ $\times \times \times \times \times \times \times \times \times \times \times \times \times \times \times \times \times \times$ $\times \times \times \times \times \times \times \times \times \times \times \times \times \times$ $\times \times \times \times \times \times \times \times \times \times \times \times \times \times \times \times \times \times \times \times \times$ $\times \times \times \times \times \times \times \times \times \times \times \times \times \times \times \times \times \times \times \times \times$ $\times \times \times \times \times \times \times \times \times \times \times \times \times \times \times \times \times \times \times \times \times$

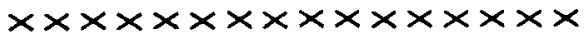
$\times \times \times \times \times \times \times \times \times \times \times \times \times \times \times \times \times \times \times \times \times \times \times \times \times$ $\times \times \times \times \times \times \times \times \times \times \times \times \times \times \times \times \times \times$ $\times \times \times \times \times \times \times \times \times \times \times \times \times \times \times \times \times \times$

$$
x \times x
$$

$\times \times \times \times \times \times \times \times \times \times \times \times \times \times \times \times \times$ $\times \times \times \times \times \times \times \times \times \times \times \times \times \times \times \times \times$ $\times \times \times \times \times \times \times \times \times \times \times \times \times \times \times \times \times$ $\times \times \times \times \times \times$ $x \times x \times x \times$
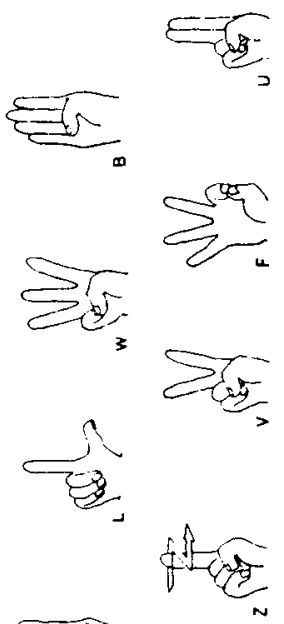

दo

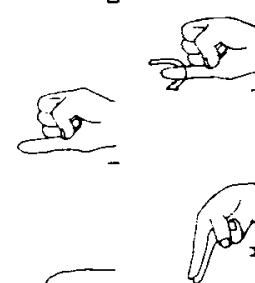

$\sum_{3}^{3}$

$\underbrace{-x^{2}}_{0}$

$\int_{0}$

Sho

$\sqrt{y_{x}}$

$\sum \sqrt{a^{2}}$

$\frac{8}{8 x}$

8
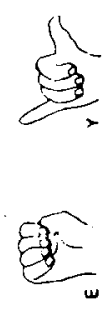

है?

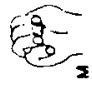

8

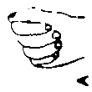

$\sqrt{3}$

(a) 
be more strongly clustered than $\mathrm{A}$ and $\mathrm{T}$, which are more strongly clustered than $\mathrm{C}$ and $\mathrm{O}$, and so forth.

It can be seen that only one cluster combines an appreciable number of handshapes; $A, T, M, N, E$, and $S$ form a group characterized by compactness. Most of the remaining clusters-handshape pairs-appear to be grouped on the basis of a single essential similarity: For the pairs K-P, G-Q, I-J, and D-Z, the letters are formed by identical shapes, which differ only in orientation (K-P, G-Q) or movement (I-J, D-Z); the pair C-O represents two degrees of what might be called hand closure, other aspects (orientation, finger configuration) being the same; and the pairs V-W and B-U differ only in the number of fingers extending upward.

To supplement this cluster-based description, the data were examined for dimensionality and spatially interpretable structure using a nonmetric multidimensional scaling (MDS) procedure (as developed by Kruskal, 1964, and Shepard, 1962). Although a stress analysis suggested no clearly appropriate dimensionality, ease of interpretation leads us to prefer the unrotated two-dimensional solution depicted in Figure 3.

Several aspects of this solution warrant comment. We see the horizontal dimension as representing hand compactness with open or extended handshapes on the left and closed handshapes on the right. The vertical dimension seems best characterized as orientation of the hand's major axis with vertically oriented handshapes near the top and horizontally oriented ones near the bottom. The distribution of the handshapes within this space is somewhat fan like; closed handshapes cluster tightly in the orientation dimension (much more so than can be represented in this figure), whereas open or extended ones are widely dispersed. Another way to say this is that to the extent that closed handshapes have an orientation, it is common to them all.
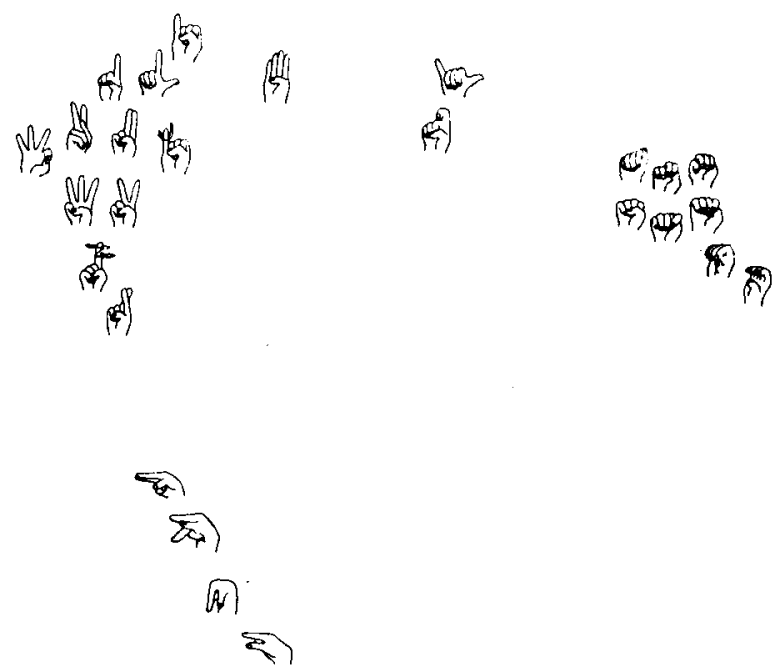

Figure 3. The two-dimensional MDS solution for the handshapes in Experiment 1.

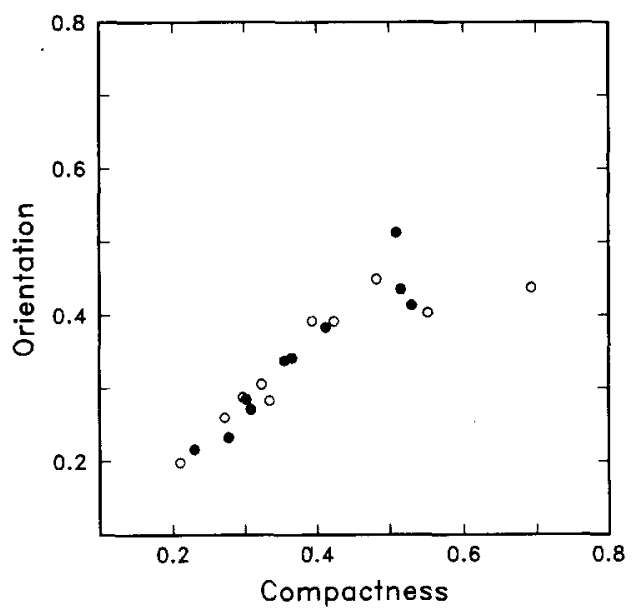

Figure 4. Individual subject's weightings on the two dimensions of orientation and compactness in Experiment 1. Filled circles represent native signers of $\mathrm{ASL}$, open circles represent nonnative signers.

Finally, an INDSCAL analysis of the individual dissimilarity matrices found no evidence for different organizations as a function of whether ASL was the subject's native language. This may be seen in Figure 4, which plots each subject's weights on the two dimensions of compactness and orientation. There is no evidence that the native signers (filled circles) differ from the nonnative signers (open circles) in their dimensional weightings.

\section{EXPERIMENT 2}

In the second experiment, similarity judgments were based on the essentially kinesthetic aspects of manual handshape production. To help ensure this, uppercase letters were used as stimuli (forcing subjects to generate, either overtly or covertly, the handshapes being compared at any point during the sorting task). Instructions emphasized that production similarity was to be assessed. In other respects, the second experiment was identical to the first.

\section{Method}

Stimuli. Stimuli were the uppercase representations of the 26 letters of the alphabet. Each character was printed, in 30-point lettering, on a $3 \times 5$ in. index card.

Procedure. The procedure was similar to that of Experiment 1. For this experiment, the subjects were instructed to sort the cards into piles on the basis of the similarity of the handshapes. Written instructions were given to the subjects, and a deaf experimenter (the same person as in Experiment 1) reviewed the instructions with the subjects to ensure that they were understood. The written instructions were as follows: "The 26 letters of the alphabet are laid out in front of you. Begin by thinking about the handshapes for each letter. Then put the letters into piles, so that letters that have handshapes that are similar to produce are in the same pile. You can have as many piles as you wish and you can have any number of letters in each pile. You can change your mind as often as you like until your arrangement seems best. REMEMBER TO THINK 
Table 2

Number of Subjects Sorting Handshape Pairs Into Same Pile on the Basis of Production Similarity in Experiment 2

\begin{tabular}{|c|c|c|c|c|c|c|c|c|c|c|c|c|c|c|c|c|c|c|c|c|c|c|c|c|c|}
\hline & A & B & C & D & $\mathrm{E}$ & $\mathbf{F}$ & $\mathrm{G}$ & $\mathbf{H}$ & I & $\mathbf{J}$ & $\mathbf{K}$ & $\mathbf{L}$ & $\mathbf{M}$ & $\mathbf{N}$ & $\mathrm{O}$ & $\mathbf{P}$ & $\mathrm{Q}$ & $\mathbf{R}$ & $\mathbf{S}$ & $\mathbf{T}$ & $\mathrm{U}$ & $\mathrm{V}$ & w & $X$ & $\bar{Y}$ \\
\hline B & 0 & & & & & & & & & & & & & & & & & & & & & & & & \\
\hline $\mathrm{C}$ & 4 & 0 & & & & & & & & & & & & & & & & & & & & & & & \\
\hline D & 1 & 4 & 4 & & & & & & & & & & & & & & & & & & & & & & \\
\hline E & 11 & 2 & 6 & 4 & & & & & & & & & & & & & & & & & & & & & \\
\hline F & 0 & 7 & 0 & 4 & 3 & & & & & & & & & & & & & & & & & & & & \\
\hline $\mathbf{G}$ & 0 & 1 & 3 & 0 & 1 & 3 & & & & & & & & & & & & & & & & & & & \\
\hline H & 1 & 2 & 2 & 1 & 3 & 2 & 8 & & & & & & & & & & & & & & & & & & \\
\hline I & 1 & 1 & 1 & 1 & 1 & 1 & 1 & 1 & & & & & & & & & & & & & & & & & \\
\hline $\mathbf{J}$ & 0 & 1 & 0 & 0 & 0 & 1 & 1 & 1 & 15 & & & & & & & & & & & & & & & & \\
\hline $\mathbf{K}$ & 0 & 1 & 0 & 0 & 0 & 1 & 0 & 1 & 1 & 0 & & & & & & & & & & & & & & & \\
\hline L & 0 & 2 & 0 & 5 & 0 & 2 & 2 & 1 & 8 & 6 & 2 & & & & & & & & & & & & & & \\
\hline $\mathbf{M}$ & 3 & 2 & 1 & 1 & 2 & 0 & 1 & 3 & 0 & 0 & 0 & 0 & & & & & & & & & & & & & \\
\hline $\mathbf{N}$ & 2 & 2 & 1 & 1 & 2 & 0 & 1 & 3 & 0 & 0 & 1 & 0 & 18 & & & & & & & & & & & & \\
\hline 0 & 6 & 0 & 12 & 3 & 6 & 0 & 2 & 1 & 1 & 0 & 0 & 0 & 1 & 1 & & & & & & & & & & & \\
\hline $\mathbf{P}$ & 0 & 2 & 0 & 2 & 1 & 3 & 1 & 1 & 0 & 0 & 14 & 1 & 0 & 0 & 0 & & & & & & & & & & \\
\hline $\mathbf{Q}$ & 0 & 0 & 3 & 1 & 0 & 2 & 14 & 5 & 0 & 0 & 0 & 1 & 0 & 0 & 4 & 2 & & & & & & & & & \\
\hline $\mathbf{R}$ & 0 & 5 & 0 & 3 & 2 & 6 & 3 & 3 & 1 & 1 & 2 & 3 & 0 & 0 & 0 & 3 & 2 & & & & & & & & \\
\hline $\mathbf{S}$ & 16 & 0 & 4 & 1 & 10 & 0 & 0 & 1 & 1 & 0 & 0 & 0 & 2 & 2 & 5 & 0 & 0 & 0 & & & & & & & \\
\hline $\mathbf{T}$ & 7 & 0 & 3 & 2 & 5 & 0 & 1 & 2 & 2 & 2 & 0 & 2 & 8 & 8 & 1 & 1 & 0 & 0 & 8 & & & & & & \\
\hline $\mathrm{U}$ & 0 & 1 & 1 & 0 & 0 & 0 & 1 & 6 & 0 & 0 & 0 & 0 & 2 & 2 & 1 & 0 & 1 & 1 & 0 & 1 & & & & & \\
\hline V & 1 & 1 & 0 & 0 & 0 & 0 & 0 & 2 & 0 & 0 & 0 & 0 & 2 & 1 & 0 & 0 & 0 & 1 & 0 & 1 & 13 & & & & \\
\hline W & 1 & 2 & 0 & 0 & 0 & 1 & 0 & 1 & 0 & 0 & 0 & 0 & 1 & 0 & 0 & 0 & 0 & 1 & 0 & 1 & 11 & 17 & & & \\
\hline$X$ & 5 & 0 & 2 & 2 & 3 & 0 & $\mathbf{0}$ & 1 & 0 & 1 & 0 & 1 & 2 & 1 & 1 & 1 & 0 & 0 & 4 & 4 & 2 & 2 & 2 & & \\
\hline$Y$ & 2 & 0 & 0 & 1 & 1 & 0 & 0 & 0 & 2 & 3 & 0 & 2 & 2 & 1 & 0 & 1 & 1 & 0 & 1 & 2 & 3 & 4 & 4 & 4 & \\
\hline Z & 1 & 1 & 0 & 4 & 1 & 1 & 1 & 2 & 2 & 6 & 1 & 3 & 0 & 1 & 0 & 1 & 0 & 1 & 1 & 3 & 1 & 1 & 1 & 7 & 5 \\
\hline
\end{tabular}

ABOUT EACH HANDSHAPE AND GROUP THE LETTERS ACCORDING TO SIMILARITY OF THE HANDSHAPES.",

Subjects. Twenty deaf students from Gallaudet College were tested; half were native signers of ASL, the other half were not. The data of one of the nonnative signers were eliminated from analysis due to an apparent failure to follow the instructions (the sorting of this subject was based on the visual similarity of the printed letters rather than on the production similarity of the handshapes, as evidenced by clusters such as W-M, X-K, F-E, and A-H). The remaining nine nonnative signers reported a minimum of 13 years' signing experience. On the average, they had learned to sign at the age of 5.3 years; the mean length of signing experience for these subjects was 17.1 years. All subjects were paid for their participation in this 15 -min experiment.

\section{Results and Discussion}

Table 2 summarizes the number of subjects who sorted a given handshape pair into the same pile (19 being the maximum possible similarity score). As in the first experiment, these data were subjected to a hierarchical clustering analysis; the result is shown in Figure 5.

In slight contrast to the first experiment, these data appear to possess less global structure. In particular, the compact handshapes (A, T, M, N, E, A, S) exhibit no tendency to cluster as a single group. Rather, two smaller clusters emerge, each being describable in productionrelevant terms: The $\mathrm{E}, \mathrm{A}$, and $\mathrm{S}$ handshapes share the position of the four fingers, differing only in thumb placement relative to the finger group; the $\mathrm{M}, \mathrm{N}$, and $\mathrm{T}$ handshapes differ only in the number of fingers extended over the thumb, with $\mathrm{M}$ having three, $\mathrm{N}$ having two, and $\mathrm{T}$ having only one. With this exception, the remaining clusters-pairs once again-are primarily grouped as be- fore. This similarity between the results of Experiments 1 and 2 is further supported by a moderately large correlation between the matrices shown in Tables 1 and 2 $(\mathrm{r}=.66, \mathrm{df}=323, \mathrm{p}<.01)$.

The dimensionality and spatial structure of these data were next analyzed using an MDS procedure. The twodimensional solution shown in Figure 6 exhibits many of the same characteristics as before. The horizontal dimension represents hand compactness with open or extended handshapes on the left and closed handshapes on the right. The vertical dimension represents orientation of the hand's major axis with vertically oriented handshapes near the top and horizontally oriented ones near the bottom. And although the distribution of the handshapes within this space is somewhat more uniform than in Experiment 1, we view the two solutions as essentially similar.

Further evidence of this similarity derives from a comparison with the solution obtained by Weyer (1973) for visual handshape confusability. Although Weyer did not choose to interpret the two dimensions of his solution, they correspond to the dimensions of compactness and orientation found here. Moreover, the distribution of handshapes within the space is very similar to the distribution shown in Figure 6 (with the only significant exception being a left-right reflection of the compactness dimension). We conclude from this that production similarity and visual similarity are structurally similar.

Finally, we found no evidence for different organizations as a function of whether ASL was the subject's native language. An INDSCAL analysis suggested, as before, that the groups were similarly dispersed within the space of dimensional weights. This is shown in Figure 7. 
$\times \times \times \times \times \times \times \times \times \times \times \times \times \times \times \times \times \times \times 1$

$\times \times \times \times \times \times \times \times \times \times \times \times$

$\times \times \times \times \times \times \times \times \times \times \times \times \times \times \times \times \times \times$ $\times \times \times \times \times \times \times \times \times \times \times \times \times \times \times \times \times \times$ $\times \times \times \times \times \times \times \times \times \times \times \times \times \times \times \times \times \times$ $x \times$ $\times \times \times \times \times \times \times \times$ $\times \times \times \times \times \times \times \times$ $\times \times \times \times \times \times \times \times$ $\times \times \times \times \times$ $\times \times \times \times \times$

$x$

$x \times x \times$

$x \times x \times$ $\times \times \times \times \times \times$ $\times \times \times \times \times \times$ $\times \times \times \times \times \times \times \times$ $\times \times \times \times \times \times \times \times$ $\times \times \times \times \times \times \times x$

$x$

$\times \times \times \times \times \times \times$

$\times \times \times \times \times \times \times$

$\times \times \times \times \times \times \times \times \times \times \times \times \times \times \times \times$ $\times \times \times \times \times \times \times \times \times \times \times \times \times \times \times \times$ $\times \times \times \times \times \times \times \times \times \times \times \times \times \times \times \times$ $x \times x \times x \times x \times x \times x \times x \times x \times x \times x$ $\times \times \times \times \times \times \times \times \times \times \times \times \times \times \times$ $\times \times \times \times \times \times \times \times \times \times \times \times \times \times \times$ $\times \times \times \times \times \times \times \times \times \times \times \times \times \times \times$

$x \times x \times x \times x \times x \times x \times x \times x$

$\times \times \times \times \times \times \times \times \times \times \times \times \times \times \times$ $\times \times \times \times \times \times \times \times \times \times \times \times \times \times \times$ $\times \times \times \times \times \times \times \times \times \times \times \times \times \times \times$ $\times \times \times \times \times \times$ $x \times x \times x \times$

$x \times \times \times \times \times \times \times \times$ $\times \times \times \times \times \times \times \times \times$ $\times \times \times \times \times \times \times \times \times \times \times \times \times \times \times \times \times \times \times$ $\times \times \times \times \times \times \times \times \times \times \times \times \times \times \times \times \times \times \times$ $\times \times \times \times \times \times \times \times \times \times \times \times \times \times \times \times \times \times \times$

$x \times$

$\times \times \times \times \times \times \times \times \times \times \times \times \times \times \times \times \times$ $\times \times \times \times \times \times \times \times \times \times \times \times \times \times \times \times \times$ $\times \times \times \times \times \times \times \times \times \times \times \times \times \times \times \times \times$ $\times \times \times \times \times \times \times \times \times \times \times$ $\times \times \times \times \times \times \times \times \times \times \times$ $\times \times \times \times \times$ $\times \times \times \times \times \times \times \times \times \times \times \times \times$ $\times \times \times \times \times \times \times \times \times \times \times \times \times$ $\times \times \times \times \times \times \times \times \times \times \times \times \times$<smiles>c1ccccc1</smiles><smiles>c1cc2cc(c1)C2</smiles><smiles>c1ccc(N2CCCC2)cc1</smiles><smiles>c1ccccc1</smiles>

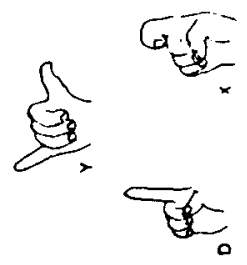<smiles>Cc1ccccc1</smiles><smiles>Cc1ccccc1</smiles><smiles>C=CCCCCCCCCCCCC</smiles>

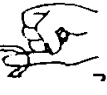<smiles>c1ccc(C23CC4CC(CC(C4)C2)C3)cc1</smiles>

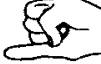<smiles>C1CCCCC1</smiles><smiles>C1=CCC=C1</smiles>

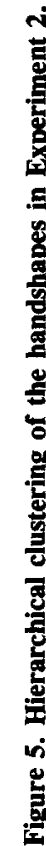<smiles>C1C2C3C4C1C1C2C3C41</smiles><smiles>CCC[Si]1CCCCC1</smiles><smiles>[CH]1C2=CC=C1C=C2</smiles><smiles>c1ccccc1</smiles>

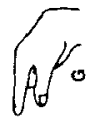<smiles>c1ccncc1</smiles>

bif<smiles>C1CCCCC1</smiles>

E)<smiles>C1=CC2CC1C1CCC21</smiles><smiles></smiles>

E 


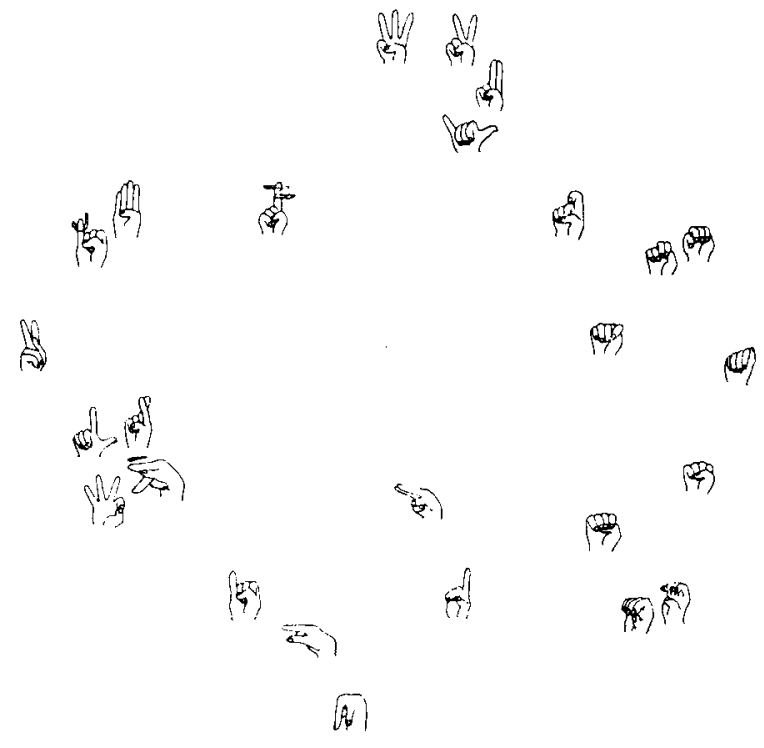

Figure 6. The two-dimensional MDS solution for the handshapes in Experiment 2.

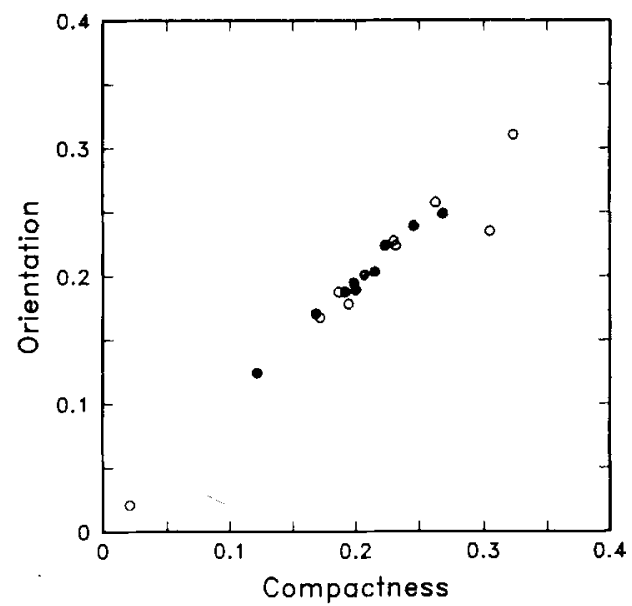

Figure 7. Individual subject's weightings on the two dimensions of orientation and compactness in Experiment 2. Filled circles represent native signers of $A S L$, open circles represent nonnative signers.

\section{GENERAL DISCUSSION}

In the two experiments reported here, visual and production similarity for the handshapes of the American manual alphabet were determined to be essentially the same. For both sets of judgments, the dimensions of hand compactness and orientation were found to describe the data. And for both sets of judgments, similar numbers and arrangements of handshape clusters emerged. We conclude from this that judged handshape similarity is relatively unaffected by the modality to which the judge attends. The present results also suggest that at least within the range of relatively skilled signers, perceived hand- shape similarity does not vary as a function of degree of experience with fingerspelling; we found no differences between native and nonnative deaf signers.

The present data are quite consistent with earlier studies of perceptual confusability. They are in accord with results reported for the subset of manual alphabet handshapes included in the ASL studies of Lane et al. (1976) and Stungis (1981). In these two studies, the major differentiating feature was whether fingers were extended (open) or not extended (compact).

The present data are also in accord with the results obtained by Weyer (1973) for the entire manual alphabet. Weyer investigated the confusions that emerged during tachistoscopic recognition of computer-generated handshapes. His clustering analysis indicated that the largest cluster was composed of the $\mathrm{N}, \mathrm{S}, \mathrm{T}$, and A handshapes, with an adjacent cluster composed of the the E, M, and $\mathrm{O}$ handshapes. These handshapes, characterized by Weyer as involving fists and folding fingers, are the same as those found by our analyses to be "compact." Some of the smaller clusters found by Weyer were also apparent in the visual similarity data of the present Experiment 1, for example, B-U, V-W, and I-J. Some differences did arise, however, in specific clusterings of handshape pairs. We found, for example, that our deaf subjects judged, as visually similar, pairs that had similar shapes but differed in orientation (K-P, G-Q) or movement (D-Z). These groupings were not obtained by Weyer. Such differences might be attributed to procedural variation (Weyer used tachistoscopic recognition; we used a sorting task), or to differences in the handshape stimuli used, or to subject differences. To the extent that the differences are reliable, we suspect that subjects' differing familiarity with the manual alphabet underlies them. Twelve of the 15 subjects in Weyer's study were hearing, and the level of fingerspelling expertise was given for none of the subjects. It is possible that his hearing subjects were totally unfamiliar with fingerspelling prior to the experiment. If so, they would have tended to rely on visual features, whereas our more experienced subjects might have allowed their knowledge of handshape production (e.g., $\mathrm{K}$ and $\mathrm{P}$ are the same handshape, just oriented differently) to influence their judgments.

The present data are consistent, moreover, with patterns of interletter confusion obtained in tasks requiring the short-term retention of printed letter strings. Two studies, one by Conrad and Rush (1965) and another by Wallace and Corballis (1973), examined short-term retention by deaf subjects with manual language experience (and published the raw confusion matrices needed here). Of these two, only the one by Wallace and Corballis included, in the stimulus set, a high proportion of letters found by our techniques to be manually similar. ${ }^{3}$ From this fact alone we might expect that the confusion data of Conrad and Rush would be less influenced by manual similarity than the data of Wallace and Corballis. The correlations summarized in Table 3 are in line with this expectation (note that the results in this table were de- 
Table 3

Correlations of STM Confusion Matrices with Manual Similarity Matrices

\begin{tabular}{lccc}
\hline & \multicolumn{3}{c}{ Manual Similarity Matrix } \\
\cline { 2 - 4 } STM Confusion Matrix & Visual & Production & Combined \\
\hline Conrad \& Rush (1965) & -.17 & .06 & -.08 \\
Wallace \& Corballis (1973) & $.45 \dagger$ & $.51 \dagger$ & $.50 \dagger$ \\
\hline
\end{tabular}

†Significant at .01 level or better.

rived by correlating the interletter confusion matrices, collapsed across conditions within each of the two studies, with the subset of our manual similarity matrices containing the letter subset used in each of the two studies). We find an interpretable pattern of correlations within the conditions of the Wallace and Corballis study as well. In Table 4 , separate correlations are shown for stimulus strings of length 4 and 5 for subjects with manual training and for those with oral training. The higher correlations for the longer stimulus strings may well correspond to a greater reliance on language codes in short-term memory. The higher correlations for the manual subject group may well reflect a greater tendency to associate the printed letter strings with the corresponding handshapes (a tendency made all the more likely by their history of instruction in the Rochester method-a technique in which all words are fingerspelled). These two trends are even more apparent in the right half of the table. Here we show the correlations between confusion and similarity matrices from which the letter pair G-Q has been excluded. Since Wallace and Corballis noted that the lowercase forms of their stimulus letters $G$ and $Q$ were highly similar visually (differing only in a right- vs. left-hooking descender), and since these two letters are also quite similar manually (same handshape in different orientation), this exclusion affords a clearer picture of the relationship due to manual similarity alone.

The present results are not consistent with the production similarity data obtained by Locke (1970). Locke found the following pairs of handshapes to be rated as the most similar kinesthetically: K-P, B-Y, F-B, R-P, $T-V$, and $X-K$. Of these pairs, our subjects judged only the pair K-P to be highly similar. The pair F-B was judged to be moderately similar. It is likely that the limited set of nine letters used by Locke, combined with a forcedchoice methodology, imposed a set of similarity relation-

Table 4

Correlations of STM Confusion Matrices (from Wallace \& Corballis, 1973) with Combined Manual Similarity Matrix

\begin{tabular}{|c|c|c|c|}
\hline \multirow[b]{2}{*}{ STM Confusion } & \multirow[b]{2}{*}{ Matrix } & \multicolumn{2}{|c|}{ Letter Set } \\
\hline & & Including G-Q & Excluding G-Q \\
\hline \multicolumn{4}{|c|}{ Manually Trained Subjects } \\
\hline List Length 4 & . & $.38 t$ & .07 \\
\hline List Length 5 & & $.48 \dagger$ & $.45 \dagger$ \\
\hline \multicolumn{4}{|c|}{ Orally Trained Subjects } \\
\hline List Length 4 & & $.29 *$ & -.06 \\
\hline List Length 5 & & $.37 *$ & $.20^{*}$ \\
\hline
\end{tabular}

*Significant at .05 level or better. +Significant at .01 level or better. ships unrepresentative of the larger set of handshapes. It is also possible that subjects misinterpreted his instructions. Consider, for example, that the letter pair T-V was rated highly similar by Locke's subjects (in contrast to Weyer's study and the present one, which are the only other studies to include both the $\mathrm{T}$ and $\mathrm{V}$ handshapes). This letter combination is frequently produced by deaf individuals (in referring to television) and is quite easy to produce as a rapid sequence. If such an "ease of coproduction' 'criterion was adopted by Locke's subjects, there would be little reason to expect our results to be similar.

In summary, our characterization of handshape similarity appears reasonably stable across both judgment modality and degree of experience. It is consistent with previous work in perceptual confusability and is related in straightforward ways to patterns of interletter confusion in short-term memory. Future experiments can draw on these results to systematically manipulate or detect the use of manual codes in the processing of verbal stimuli.

\section{REFERENCES}

Bellugi, U., Klima, E. S., \& Siple, P. (1975). Remembering in signs. Cognition, 3, 93-125.

Conrad, R. (1964). Acoustic confusions in immediate memory. British Journal of Psychology, 55, 75-84.

CONRAD, R. (1979). The deaf schoolchild. London: Harper \& Row.

ConRad, R., \& Rush, M. L. (1965). On the nature of short-term encoding by the deaf. Journal of Speech and Hearing Disorders, 30 , 336-343.

Dodd, B., \& Hermelin, B. (1977). Phonological coding by the prelinguistically deaf. Perception \& Psychophysics, 21, 413-417.

FurTh, H. G. (1973). Deafness and learning. Belmont, CA: Wadsworth. Hanson, V. L. (1982a). Short-term recall by deaf signers of American Sign Language: Implications for order recall. Journal of Experimental Psychology: Learning, Memory, \& Cognition, 8, 572-583.

HaNSON, V. L. (1982b). Use of orthographic structure by deaf adults: Recognition of fingerspelled words. Applied Psycholinguistics, 3, 343-356.

Hanson, V. L., Liberman, I. Y, \& Shankweiler, D. (1984). Linguistic coding by deaf children in relation to beginning reading success. Journal of Experimental Child Psychology, 37, 378-393.

Johnson, S. C. (1967). Hierarchical clustering schemes. Psychometrika. 32, 241-254.

Klima, E., \& Bellugi, U. (1979). The signs of language. Cambridge, MA: Harvard University Press.

KrUSKAL, J. B. (1964). Multidimensional scaling by optimizing goodness of fit to a nonmetric hypothesis. Psychometrika, 29, 1-27.

Lane, H., Boyes-Braem, P., \& Bellugi, U. (1976). Preliminaries to a distinctive feature analysis of handshapes in American Sign Language. Cognitive Psychology, 8, 263-289.

LOCKE, J. L. (1970). Short-term memory encoding strategies of the deaf. Psychonomic Science, 18, 233-234. 
LOCKE, J. L., \& LOCKE, V. L. (1971). Deaf children's phonetic, visual, and dactylic coding in a grapheme recall task. Journal of Experimental Psychology, 89, 142-146.

Miller, G. A., \& Nicely, P. E. (1955). An analysis of perceptual confusions among some English consonants. Journal of the Acoustical Society of America, 27, 338-352.

Neville, H. J., Kutas, M., \& Schmidt, A. (1982). Event-related potential studies of cerebral specialization during reading. Brain \& Language, 16, 316-337.

QUINN, L. (1981). Reading skills of hearing and congenitally deaf children. Journal of Experimental Child Psychology, 32, 139-161.

REICH, P. A. (1974). Visible distinctive features. In A. Makkai \& V. B. Makkai (Eds.), The First LACUS Forum (pp. 348-356). Columbia, SC: Hornbeam Press.

SHEPARD, R. N. (1962). Analysis of proximities: Multidimensional scaling with an unknown distance function. Psychometrika, 27, 125-140, 219-246.

Stokoe, W. C., Casterline, D. C., \& Croneberg, C. G. (1965). A dictionary of American Sign Language. Washington, DC: Gallaudet College Press.

STUNGIS, J. (1981). Identification and discrimination of handshape in American Sign Language. Perception \& Psychophysics, 29, 261-276.

Treiman, R., \& Hirsh-PASeK, K. (1983). Silent reading: Insights from congenitally deaf readers. Cognitive Psychology, 15, 39-65.

Wallace, G., \& Corballis, M. C. (1973). Short-term memory and coding strategies in the deaf. Journal of Experimental Psychology, 99, 333-348.
WeYer, S. A. (1973). Fingerspelling by computer (Tech. Rep. No. 212). Stanford, CA: Stanford University, Institute for Mathematical Studies in the Social Sciences.

ZAKIA, R. D., \& HABER, R. N. (1971). Sequential letter and word recognition in deaf and hearing subjects. Perception \& Psychophysics, 9 , $110-114$.

\section{NOTES}

1. In skilled fingerspelling, letters of words are neither produced nor recognized as isolated letters. Rather, one finds evidence for coarticulatory effects in production (Reich, 1974) and facilitation of recognition in familiar clusters (Hanson, 1982b; Zakia \& Haber, 1971).

2. The subjects in Weyer's experiment were 12 hearing subjects and 3 deaf subjects. Since the data of the deaf and hearing subjects were not presented separately, we do not know to what extent the overall characterization is representative of the deaf users of the language system.

3. The study by Conrad and Rush (1965) used only 9 different letters: B, F, K, P, R, T, V, X, and Y. The study by Wallace and Corballis (1973) used only 10 letters: A, B, D, E, G, H, N, Q, R, and $T$. If we look at the visual and production similarity judgments obtained in the present study, it can be seen that the letters used by Conrad and Rush are relatively low in rated similarity (with the exception of $K$ and $P$, which are moderately similar). The letters used by Wallace and Corballis have several pairs that were found by our techniques to be manually similar (namely, A-E, A-N, A-T, N-T, and G-Q).

(Manuscript received December 26, 1984; revision accepted for publication October 7,1985 .) 